\title{
Living donor nephrectomy
}

\author{
Author: Brazilian Society of Urology \\ Antonio Silvinato ${ }^{\star 3}$, (iD Wanderley M. Bernardo*1,2, Luis Sérgio Santos ${ }^{\star *}$ \\ Final version: March 4th, 2018 \\ 1. Lecturer Professor of School of Medicine of USP; São Paulo, SP, Brasil \\ 2. Coordinator of the Brazilian Medical Association Guidelines Program, São Paulo, SP, Brasil \\ 3. Author and member of the Guidelines Program of the Brazilian Medical Association, São Paulo, Brasil \\ 4. Reviewer and member of the Guidelines Program of the Brazilian Medical Association, São Paulo, Brasil \\ *Author \\ ${ }^{\star *}$ Reviewer \\ This guideline replaces the previous 2016 version
}

The Guidelines Project, an initiative of the Brazilian Medical Association, aims to combine information from the medical field in order to standardize producers to assist the reasoning and decision-making of doctors.

The information provided through this project must be assessed and criticized by the physician responsible for the conduct that will be adopted, depending on the conditions and the clinical status of each patient.

Living donor nephrectomy can be carried out through conventional open access, mini-incision, laparoscopy, assisted by robotics, single-site (LESS), or natural orifices (NOTES). The purpose of this guideline is to present the doctors, specialists and healthcare establishments with the prominent evidence available on the best technique for living donor nephrectomy. For this, a systematic review of the literature was performed, without period restriction, in the Medline database, retrieving 322 papers, of which 28 were selected to respond to clinical doubt. The details about the methodology and the results are set out in Appendix I.

\section{INTRODUCTION}

LIVING DONOR NEPHRECTOMY can be carried out through conventional open access, mini-incision, pure or hand-assisted laparoscopy (transperitoneal or retroperitoneal), assisted by robotics, single-site (LESS), natural orifices (NOTES). Regardless of the technique, the choice of kidney must comply with severe anatomical criteria and the healthier kidney must always remain with the donor. In cas- es of equal health conditions, the priority is to remove the left kidney.

In conventional open nephrectomy, the patient is positioned in lateral decubitus, and an oblique lumbar incision is made. The peritoneum is bluntly dissected and medially reflected, gaining access to the retroperitoneal space and the kidney. For an open nephrectomy through mini-incision, the patient is placed in the same previous position, and the mini-incision is made, which can be subcostal, horizontal or vertical. Separation without incision is preferred to muscle section and the extraction of ribs is avoided. When we opt for a transperitoneal laparoscopic nephrectomy, after the complete separation of the kidney, ureter, and renal vessels, a mini Pfannenstiel incision is made, through which the organ will be removed. Renal vessels should be, preferably, connected using, at least, two clamps on each of them.

In retroperitoneal laparoscopic nephrectomy, with the patient in lateral decubitus, the workspace is created through digital or balloon dilation. The trocars are placed, and renal and vascular dissection is conducted as previously described. Hand-assisted laparoscopic nephrectomy can be conducted via a 
trans or retroperitoneal approach. The surgery begins with an incision to place the device and introduce the hand. The kidney and the vessels are laparoscopically dissected with manual aid. Renal extraction is made through the hand-insertion device. In robot-assisted laparoscopic nephrectomy, the donor is laterally positioned, and four portals are used, two for the surgeon, one for the camera and another for the assistant. The surgeon operates outside the surgical field, with a magnified 3D view, and the robotic arms offer an amplitude of movements similar to those of the human fist. Surgery lengths are the same as described and the kidney can be removed through a midline incision. Single-site (LESS) or natural orifices (NOTES) laparoscopic nephrectomy, with fewer or no scars, has also been used in living donor nephrectomy. The procedure requires special equipment, but its steps are similar to the ones previously described.

\section{RESULTS}

Is there an advantage in living donor nephrectomy through mini-incision over lumbotomy?

Several randomized studies have been published comparing living donor nephrectomy through mini-incision and conventional and laparoscopic open surgery. The mini-incision can be anterior, flank, or posterior. When compared with the conventional lumbotomy, the mini-incision showed: increase in surgery time $(p=0.02)$, less bleeding $(p=0.01)$, reduction in the use of analgesics and decrease in length of hospital stay $(p<0.0001)$. There was no difference in the number of postoperative complications $(\mathrm{p}=1.00)$ and significant difference in the level of serum creatinine in the receiver after up to 30 days $\mathbf{s}^{\mathbf{1 , 2}} \mathbf{( B )}$. When compared with the laparoscopic surgery, in two studies, there was an increase in: use of analgesics, length of surgery and recovery, as well as warm ischemia time $(p<0.05$ for all comparisons). No differences were found in the results from kidney function on the receiver and in the number of postoperative and surgical complications for any of the three techniques ${ }^{3.4}(\mathbf{A})$.

In a recent retrospective cohort study, the mini-incision, compared with laparoscopic surgery, reduced the length of surgery (53.9 $\min$ [40-75] versus 93.7 minutes (75-140), $\mathrm{p}<0.001)$, warm ischemia time (2.14 vs $2.66 \mathrm{~min} \min ; \mathrm{p}<0.001$ ), and length of hospital stay (2.44 vs 3.28 days; $p<0.001$ ). There were no significant differences in the scores for pain, graft function, or quality of life between the two groups ${ }^{5}(\mathbf{B})$.

\section{RECOMMENDATION}

Nephrectomy through mini-incision is an acceptable alternative to conventional lumbotomy for living donors. (A)

Are there advantages in using hand-assisted laparoscopic or pure laparoscopic nephrectomy, for living donors, in comparison with the conventional open approach?

\section{Hand-assisted vs. Open}

A retrospective cohort study compared the hand-assisted laparoscopic nephrectomy with a living donor (HALN) and conventional open nephrectomy (ON). In comparison with ON, HALN reduced intraoperative bleeding $(274.4 \pm 198.1$ vs $202.99 \pm$ $157.1 \mathrm{ml} ; \mathrm{p}<0.05)$, and length of hospital stay (5.58 \pm 2.2 vs. $4.23 \pm 1.8, \mathrm{p}<0.05)$, but increased the length of surgery (270 vs $217 \pm 60.1 \pm 57.5$ minutes, $p<0.05$ ) and the warm ischemia time $(4.62 \pm 2.7$ vs $2.12 \pm 1.4$ minute, $\mathrm{p}<0.05)$. There were no significant differences in surgical complications after up to 30 days or in need for transfusion ( $p>0.05$ for both comparisons). There was no reported loss of graft and no difference in kidney function between the groups, at days 1-2, or months 1, 6, or 12, after the nephrectomy ${ }^{6}(\mathbf{B})$.

The living donor HALN was compared with the laparoscopic nephrectomy (LN) in a meta-analysis (two randomized clinical trials [RCTs] and 14 cohort studies). No difference was found in the number of complications, conversion to open nephrectomy, blood loss, graft function (assessed by four cohort studies), and length of hospital stay. Manual assistance reduced surgery lengths and warm ischemia time in the comparison with pure LN DM $=-18.3$, 95\% CI -32.9 to $-3.6, \mathrm{R} 2=94 \%$ and $\mathrm{DM}=-52.9,95 \% \mathrm{CI}-91.6$ To -14.3 , R2 $=96 \%$, respectively $)^{7.8}(\mathbf{A})$.

There were no differences in the number of complications when hand-assisted techniques (HALN and hand-assisted retroperitoneal laparoscopic nephrectomy [HARLN]) were combined and compared with the fully laparoscopic approach (OR=0.52, 95\% CI $0.33-0,83, \mathrm{R} 2=46 \%)^{7}(\mathbf{A})$.

\section{Laparoscopy vs. Open}

Despite the greater length of hospital stay and warm ischemia time, laparoscopic nephrectomy presented a shorter length of hospital stay and postoperative recovery, as well as less pain and blood loss. Return to daily activities is faster and, most impor- 
tantly, the laparoscopic nephrectomy provides the best quality of life to the donor, in comparison with conventional open surgery or even with the mini-incision approach. It presents low rates of complications and conversion $^{8-10}(\mathbf{A})$. The warm ischemia time is longer in laparoscopic nephrectomy when compared with open surgery; however, there is no difference in the final graft function ${ }^{8,9,11}(\mathbf{A})^{12}(\mathbf{B})$.

\section{Transperitoneal vs. Retroperitoneal Approach}

The transperitoneal laparoscopy approach (TPLN) is technically more straightforward, with better defined anatomical references and a larger area for work than the retroperitoneal approach.

The use of the retroperitoneal approach (RPLN) in living donor nephrectomy has the advantages of easy access to the renal vessels, improved view of the lumbar vessels, and lower interference in the abdominal organs.

A recent meta-analysis comparing both approaches showed no difference in surgery length, warm ischemia time, blood loss, intestinal lesion, chylous ascites, rates of repeated procedures, ureteral complications, and loss of graft. However, in comparison with the transperitoneal approach, the retroperitoneal approach reduced the rates of blood transfusion, the incidence of delayed graft function, vascular lesion and conversion to an open surgical approach. The length of hospital stay was longer when the retroperitoneal approach was used. Therefore, for living donor nephrectomy, RPLN might be better than TPLN ${ }^{13}(\mathbf{A})$.

Another meta-analysis compared the hand-assisted retroperitoneal laparoscopic approach (HARPLN) with TPLN for living donor nephrectomy. Seven studies (498 patients) were included in the final analysis.

HARPLN was better than TPLN in reducing the length of surgery (SMD $=-0.84,95 \%$ CI $[-1.18$ to $-0.50]$ ) and warm ischemia time (SMD $=-0.93,95 \%$ CI [-1.13 to -0.72]). There was no difference between HARPLN and TPLN in blood loss (SMD = 0.13, CI 95\% [-0.50 to 0.76]), hospital stay (SMD $=-0.27,95 \% \mathrm{CI}$ [-0.70 to 0.15]) or graft survival $(\mathrm{RR}=0.97,95 \% \mathrm{CI}$ [0.92 to 1.02]). There were also no differences in risk of intraoperative complications between the groups $(\mathrm{RR}=0.62,95 \% \mathrm{CI}$ [0.31 to 1.21$])$. When the complications from both retroperitoneal approaches (HARPLN and RPLN) were combined and compared with the transperitoneal approach, the retroperitoneal ones showed reduced complications ( $\mathrm{OR}=0.52,95 \%$ CI 0.33-0.83, $\mathrm{r} 2=0 \%)^{14}(\mathbf{A})$.

\section{RECOMMENDATION}

Living donor laparoscopic nephrectomy (transperitoneal or retroperitoneal) is a safe procedure with minimal associated mortality. (A)

Are there restrictions for living donor laparoscopic nephrectomy in special situations?

There is a discussion around right/left living donor nephrectomy. The left side is preferred because it presents a longer renal vein, whereas the right side is associated with thrombosis of the renal vein and shorter vessels.

A retrospective study identified 58,599 living-donor transplants, of which 50,483 (86.1\%) were left donor nephrectomy (LDN), and 8,116 (13.9\%) right donor nephrectomy (RDN). There was a higher incidence of delay in graft function in receptors of RDN, with an odds ratio (OR) of 1.38 (95\% CI: 1.24-1.53, $\mathrm{p}<0.0001$ ). The rates of primary failure (loss of graft within 30 days from the transplant) were similar. In the RDN group, graft thrombosis as the leading cause of graft failure, with OR of 1.48 (95\% CI: 1.18 to 1.86 , $\mathrm{p}=0.0004)$, and graft survival was significantly lower $(p=0.006$ log-rank test). For the living donor results, the conversion from laparoscopy to open was greater in the RDN group, with an OR of 2.02 (95\% CI: 1.61$2.52, \mathrm{p}<0.00001)$. There were no differences in vascular complications or the need for reoperation due to bleeding. Reoperations and readmissions were higher in the LDN group. Therefore, there are differences regarding the effectiveness and safety of right and left kidney donor nephrectomy regarding receptor studies, but these are extremely small ${ }^{15}(\mathbf{A})$.

The effectiveness and safety of right living donor laparoscopic nephrectomy (RDLN) versus the left (LDLN) were assessed using a meta-analysis. A total of 15 studies with 3,073 patients were included (left, 2,420 patients [78\%]; right, 653 patients [22\%]). In comparison with the LDLN, RDLN presented shorter length of surgery (weighted mean difference [DMP] $-13.44 \mathrm{~min}, 95 \% \mathrm{CI}-4.15$ to $-22.73 \mathrm{~min} ; \mathrm{p}=0.005)$ and less blood loss (DMP -10.53 mL; 95\% CI -3.64 to -17.43 $\mathrm{ml} ; \mathrm{p}=0.003)$. There were higher intraoperative donor complication rates in LDLN OR $=0.53 ; 95 \% \mathrm{CI}, 0.31$ to $0.92 ; p=0.03)$. There were no differences between groups regarding the length of hospital stay, delayed graft function, loss of graft after one year, conversion to open nephrectomy, need of blood transfusion for the donor, and donor or receiver postoperative complications. We can conclude that right and left living 
donor laparoscopic nephrectomy are similar in surgical outcomes and postoperative graft function ${ }^{16}(\mathbf{A})$.

The studies show that multiple-artery donor laparoscopic nephrectomy is feasible and safe. The multiplicity of arteries could be linked with a higher incidence of ureteral complications for the receiver, especially in cases of polar arteries ${ }^{17-20}(\mathbf{B})$.

A body mass index (BMI) of over 35 is usually considered a contraindication to being a donor. To determine if this is justified, a systematic review with meta-analysis compared the perioperative outcome of living donor nephrectomy between donors with high and low BMIs. Of the 14 studies analyzed, eight donor perioperative outcomes were meta-analyzed, out of which five showed no differences for different categories of BMI. Three outcomes showed mean differences (DM) favoring donors with low BMI $(\leq 29.9$ $\mathrm{kg} / \mathrm{m} 2$ ). A higher BMI increased the length of surgery (DMP $16.91 \mathrm{~min}$; 95\% CI 9.06 to 24.76 ; l2 = 29\%), donor serum creatinine (pre/postoperative) (DM 0.05 $\mathrm{mg} / \mathrm{dl} ; 95 \% \mathrm{CI} 0.01$ to $0.09 ; \mathrm{R} 2=56 \%)$ and the risk of conversion ( $\mathrm{RR}=1.69$; 95\% CI 1.12 to $2.56, \mathrm{r} 2=0 \%$ ). Thus, a high body mass index (BMI), alone, does not constitute a contraindication for nephrectomy with living donor regarding short-term outcomes ${ }^{21}(\mathbf{A})$.

\section{RECOMMENDATION}

Evidence supports laparoscopic nephrectomy, regardless of the side (right or left) and for donors with multiple arteries. As for the laparoscopic nephrectomy using obese donors ((BMI $\geq 35 \mathrm{~kg} / \mathrm{m} 2)$, a careful risk assessment should be conducted, and its use should not be generalized. (A)

Are there any advantages of robot-assisted living donor laparoscopic nephrectomy?

A controlled randomized clinical trial compared the robot-assisted laparoscopic nephrectomy in living donor (RALN) and the pure laparoscopic nephrectomy (LN). A total of 45 donors (27 in the right subgroup, and 18 in the left) were randomized into two groups following the ratio of $1: 2$. There were no intraoperative complications in both groups. Compared with LN, RALN reduced pain (VAS) at 6 , 24 , and 48 hours after the surgery $(p<0.001$ for all comparisons), the need for analgesics (mg of tramadol, $p<0.001)$ and length of hospital stay $(p<0.001)$. There was a preservation of a longer arterial length of the graft when using the robot-assisted approach on the right side ( $p=0.03)$, but not on the left $(p=0.77)$. The warm ischemia time is longer in the total RALN group (right + left nephrectomy). In the analysis of the subgroups, there was an increase in the warm ischemia time for left nephrectomy $(p=0.01)$, but it wasn't different from the LN in the right nephrectomy $(p=0.24)$. There was no difference between groups regarding total length of surgery $(p=0,14)$, a decrease in hemoglobin $(\mathrm{p}=0.97)$, postoperative donor complications $(p=0.97)$ and the estimated rate of glomerular filtration of the receiver at 9 months $(p=0.64)$. Therefore, RALN is safe and facilitates the preservation of a longer length of the renal artery on the right side. However, the left RALN is associated with a longer warm ischemia time, although with no adverse outcomes of the graft ${ }^{22}(\mathrm{~A})$.

A retrospective cohort study with 05 live kidney donors who underwent right robot-assisted laparoscopic nephrectomy and 20 who underwent the conventional approach showed no difference in blood loss $(p=0.07)$, length of surgery $(\mathrm{p}=0.61)$ and warm ischemia time $(p=0.44)$. It showed no difference in the early postoperative glomerular filtration rates of the donor $(p=0.26)$ and the glomerular filtration of the receiver in the analysis at six months $(\mathrm{p}=0.53)^{23}(\mathbf{B})$.

A second retrospective cohort study with 13 living kidney donors who underwent robot-assisted laparoscopic nephrectomy and 13 who underwent the open approach showed an increase in surgery length $(p=0.0001)$ and in warm ischemia time $(p=0.0001)$ for the robot-assisted approach. There was no difference in blood loss ( $p>0.05)$ and creatinine clearance in the receivers five days after the transplant $(p>0.05)$. The robot-assisted approach reduced the length of hospital stay $(5.84 \pm 1.8 \mathrm{~d} \times 9.69 \pm 2.2 \mathrm{~d}, \mathrm{p}=0.0001)^{24}(\mathbf{B})$.

\section{RECOMMENDATION}

Robot-assisted laparoscopic nephrectomy, in living kidney donors, can be an alternative approach to open nephrectomy or pure laparoscopy.

Are there advantages in using single-site laparoscopic nephrectomy in comparison with conventional laparoscopy (I)?

A recent systematic review with meta-analysis included three controlled randomized clinical trials ${ }^{25-}$ ${ }^{27}$ (A) (179 living donors), which compared single-site laparoscopic nephrectomy in donors (LESS-DN) with pure donor laparoscopic nephrectomy in adults. 
There were no differences between LESS-DN and donor laparoscopic nephrectomy regarding mean surgery length (two studies, 79 participants: MD 6.36 min, 95\% CI -11.85 to 24.57), intraoperative blood loss (two studies, 79 participants: MD $-8.31 \mathrm{ml}, 95 \% \mathrm{CI}$ -7.09 to 23.70) or number of complications (three studies, 179 participants: ARR $=0.05,95 \% \mathrm{CI}-0.04$ to 0.14$)$.

Pain scores at discharge were lower in the LESSDN group (two studies, 79 participants: MD -1.19, 95\% CI -2.17 to -0.21$)$.

For all other outcomes, (length of hospital stay, time to return to daily activities, blood transfusions, conversion to other types of surgery, warm ischemia time, the total need of analgesics, loss of graft), there were no differences ${ }^{28}(\mathbf{A})$.

\section{RECOMMENDATION}

Any advantage of the single-site laparoscopic nephrectomy over the conventional laparoscopic nephrectomy in uncertain. (A)

\section{APPENDIX I}

\section{Clinical question}

What is the best technique for living donor nephrectomy?

\section{Eligibility criteria}

The main reasons for exclusion were: they did not respond to the PICO and study design.

Narrative reviews, case studies, series of cases, studies with preliminarily results presentations were, initially, excluded.

\section{Search for papers}

Database

The scientific database consulted was Medline (via PubMed) and the references of the selected studies.

\section{Identification of descriptors}

\begin{tabular}{|l|l|}
\hline $\mathbf{P}$ & Living kidney donor \\
\hline $\mathbf{I}$ & Nephrectomy \\
\hline $\mathbf{C}$ & Different nephrectomy techniques \\
\hline $\mathbf{O}$ & Benefit or damage \\
\hline
\end{tabular}

P (Patient); I (Intervention or Exposure); C (Comparison); O (Outcome)

\section{Research strategy}

Searches conducted until March 4th, 2018.

Medline via PubMed

\#1 (Kidney Transplantation OR Nephrectomy) AND Living Donors

\#2 (Laparotomy OR Laparoscopy OR Endoscopy OR Retroperitoneal Space OR Robotic Surgical Procedures OR robotic OR Robot-Assisted OR Robotic-Assistence OR Hand-Assisted Laparoscopy OR open donor nephrectomy OR ODN OR open nephrectomy OR laparoscopic live donor nephrectomy OR LDN)

\#3 (Random* OR Comparative study OR Comparative studies OR systematic[sb])

\#4: \#1 AND \#2 AND \#3 = 322 studies

\#5 (Nephrectomy AND Living Donors) AND (Renal Artery OR multiple Renal Artery OR multiple renal arteries $)=301$ studies

\#6 (Nephrectomy AND Living Donors) AND (BMI

OR Obesity) $=119$ studies

\#5 OR \#6 = 408 studies

Total studies included $=28$ studies

\section{Central (Cochrane)}

(Kidney Transplantation OR Nephrectomy) AND Living Donors - Included 0

Others

(Kidney Transplantation OR Nephrectomy) AND Living Donors - Included 0

\section{Critical evaluation}

Relevance - clinical importance

This guideline was prepared by means of a clinically relevant question to gather information in medicine to standardize approaches and assist in decision-making.

\section{Reliability - Internal validity}

The selection of the studies and the evaluation of the titles and abstracts obtained from the search strategy in the databases consulted were independently and blindly conducted, in total accordance with the inclusion and exclusion criteria. Finally, the studies with potential relevance were separated. When the title and the summary were not enlightening, we sought for the full article.

Only studies with texts available in its entirety were considered for critical evaluation.

No restriction was made regarding the year of publication. 
Languages: Portuguese, English, and Spanish.

\section{Results application - External validity}

The level of scientific evidence was classified by type of study according to Oxford ${ }^{29}$ (Table 1).

TABLE 1: GRADES FOR RECOMMENDATION AND LEVELS OF EVIDENCE

A: Experimental or observational studies of higher consistency.

B: Experimental or observational studies of lower consistency.

C: Uncontrolled case/study reports.

D: Opinion deprived of critical evaluation, based on consensus, physiological studies or animal models.

The selected evidence was defined as a randomized controlled clinical trial (RCT) and submitted to an appropriate critical evaluation checklist (Table 2). The critical evaluation of RCT allows to classify it according to the Jadad score ${ }^{30}$, considering Jadad trials $<$ three (3) as inconsistent (grade B) and those with score $\geq$ three (3) consistent (grade A).

When the evidence selected was defined as a comparative study (observational cohorts, or non-randomized clinical trial), it was subjected to an adequate critical assessment checklist (Table 3), allowing for the classification of the study according to the Newcastle Ottawa ScaleE ${ }^{31}$, which considered consistent cohort studies with scores $\geq 6$, and inconsistent $<6$.

TABLE 2 - GUIDE FOR CRITICAL EVALUATION OF RANDOMIZED CONTROLLED TRIALS

\begin{tabular}{|l|l|}
\hline $\begin{array}{l}\text { Study data } \\
\text { Reference, study design, Jadad, } \\
\text { level of evidence }\end{array}$ & $\begin{array}{l}\text { Sample size calculation } \\
\text { Estimated differences, power, } \\
\text { significance level, total num- } \\
\text { ber of patients }\end{array}$ \\
\hline $\begin{array}{l}\text { Patient selection } \\
\text { Inclusion and exclusion criteria }\end{array}$ & $\begin{array}{l}\text { Patients } \\
\text { Recruited, randomized, prog- } \\
\text { nostic differences }\end{array}$ \\
\hline $\begin{array}{l}\text { Randomization } \\
\text { Description and blinded allocation }\end{array}$ & $\begin{array}{l}\text { Patient follow-up } \\
\text { Time, losses, migration }\end{array}$ \\
\hline $\begin{array}{l}\text { Treatment protocol } \\
\text { Intervention, control, and blinding }\end{array}$ & $\begin{array}{l}\text { Analysis } \\
\text { Intention to treat, analyzed } \\
\text { intervention and control }\end{array}$ \\
\hline $\begin{array}{l}\text { Outcomes considered } \\
\text { Primary, secondary, measurement } \\
\text { instrument for the outcome of } \\
\text { interest }\end{array}$ & $\begin{array}{l}\text { Results } \\
\text { Benefits or harmful effects } \\
\text { in absolute data, benefits or } \\
\text { harmful effects on average }\end{array}$ \\
\hline
\end{tabular}

A MeaSurement Tool to Assess Reviews (Amstar) ${ }^{32}$ was used to evaluate the quality of the systematic reviews. This tool provides a global quality rating on a scale from 0 to 11 , in which 11 represents a review of the highest quality. Quality categories were determined as follows: low (0 to 3 score), medium (4 to 7 score) and high (8 to 11 score). SRs of low and medium quality were excluded.

\section{Method of extraction and result analysis}

For results with available evidence, the population, intervention, outcomes, presence or absence of benefits and/or harmful effects, and controversy will be explicitly defined whenever possible.

The results will be presented preferably in absolute data, absolute risk, the number needed to treat (NNT) or number needed to harm (NNH) and, eventually, in mean and standard deviation values (Table 4).

TABLE 4 - WORKSHEET USED FOR DESCRIBING AND PRESENTING THE RESULTS FOR EACH STUDY

\begin{tabular}{l}
\hline Evidence included \\
\hline Study design \\
\hline Selected population \\
\hline Follow-up time \\
\hline Outcomes considered \\
\hline Expression of results: percentage, risk, odds, hazard ration, mean \\
\hline
\end{tabular}

Results

Studies returned (05/2018)

TABLE 5 - NUMBER OF PAPERS RETURNED FROM THE SEARCH METHODOLOGY USED IN EACH OF THE SCIENTIFIC DATABASES

\begin{tabular}{l|l}
\begin{tabular}{ll} 
DATABASE & NUMBER OF PAPERS \\
Primary & 322 \\
\hline PubMed-Medline & \\
\hline
\end{tabular}
\end{tabular}

\section{Application of evidence - Recommendation}

The recommendations will be elaborated by the authors of the review, with the primary characteristic of the synthesis of evidence, being subject to validation by all authors who participated in creating the guideline.

TABLE 3 - GUIDE FOR CRITICAL EVALUATION OF COHORT STUDIES

\begin{tabular}{|c|c|c|c|c|c|c|}
\hline $\begin{array}{l}\text { Representativeness } \\
\text { of the exposed and } \\
\text { selection os the } \\
\text { non-exposed } \\
\text { (Max. } 2 \text { points) }\end{array}$ & $\begin{array}{l}\text { Exposure defi- } \\
\text { nition } \\
\text { (Max. } 1 \text { point) }\end{array}$ & $\begin{array}{l}\text { Demonstration that the } \\
\text { outcome of interest was } \\
\text { not present at the begin- } \\
\text { ning of the study } \\
\text { (Max. } 1 \text { point) }\end{array}$ & $\begin{array}{l}\text { Comparability } \\
\text { from the design } \\
\text { or the analysis } \\
\text { (Max. } 2 \text { points) }\end{array}$ & $\begin{array}{l}\text { Outcome } \\
\text { assessment } \\
\text { (Max.1 point) }\end{array}$ & $\begin{array}{l}\text { Adequate fol- } \\
\text { low-up time } \\
\text { (Max. } 2 \text { points) }\end{array}$ & $\begin{array}{l}\text { Scores and } \\
\text { level of evi- } \\
\text { dence }\end{array}$ \\
\hline
\end{tabular}


The available evidence will follow some principles of exposure- it will be by outcome and will have as components: number of patients, type of comparison, magnitude, and precision (standard deviation and 95\% CI).

Its strength will be estimated (Oxford ${ }^{29} / \mathrm{Grade}^{33}$ ) as $1 \mathrm{~b}$ and $1 \mathrm{c}$ (grade $\mathrm{A}$ ) or strong, and as $2 \mathrm{a}, 2 \mathrm{~b}$ and $2 \mathrm{c}$ (grade B) or moderate weak, or very weak.

\section{Conflict of interest}

There is no conflict of interest related to this review that can be declared by any of the authors.

\section{REFERENCES}

1. Kok NF, Alwayn IP, Schouten $O$, Tran KT, Weimar W, ljzermans JN Mini-incision open donor nephrectomy as an alternative to classic lumbotomy: evolution of the open approach. Transpl Int. 2006;19(6):500-5.

2. Neipp M, Jackobs S, Becker T, zu Vilsendorf AM, Winny M, Lueck R, et al. Living donor nephrectomy: flank incision versus anterior vertical mini-incision. Transplantation. 2004;78(9):1356-61.

3. Dols LF, ljzermans JN, Wentink N, Tran TC, Zuidema WC, Dooper IM, et al. Long-term follow-up of a randomized trial comparing laparoscopic and mini-incision open live donor nephrectomy. Am | Transplant. 2010;10(11):2481-7.

4. Kok NF, Lind MY, Hansson BM, Pilzecker D, Mertens zur Borg IR, et al. Comparison of laparoscopic and mini incision open donor nephrectomy: single blind, randomised controlled clinical trial. BMJ. 2006;333(7561):221.

5. Yadav K, Aggarwal S, Guleria S, Kumar R. Comparative study of laparoscopic and mini-incision open donor nephrectomy: have we heard the last word in the debate? Clin Transplant. 2016;30:328-34. PMID: 26780835

6. Villeda-Sandoval $\mathrm{Cl}$, Rodríguez-Covarrubias F, Cortés-Aguilar G, Alberú-Gómez J, Vilatobá-Chapa M, Sotomayor M, et al. Hand-assisted laparoscopic versus open donor nephrectomy: a retrospective comparison of perioperative and functional results in a tertiary care center in Mexico. Transplant Proc. 2013;45:3220-4. PMID: 24182788

7. Özdemir-van Brunschot DM, Koning GG, van Laarhoven $K C$, Ergün M, van Horne SB, Rovers MM, et al. A comparison of technique modifications in laparoscopic donor nephrectomy: a systematic review and meta-analysis. PLoS One. 2015 27;10:e0121131. PMID: 25816148

8. Yuan H, Liu L, Zheng S, Yang L, Pu C, Wei Q, et al. The safety and efficacy of laparoscopic donor nephrectomy for renal transplantation: an updated meta-analysis. Transplant Proc 2013;45:65-76. PMID: 23375276

9. Greco F, Hoda MR, Alcaraz A, Bachmann A, Hakenberg OW, Fornara P. Laparoscopic living-donor nephrectomy: analysis of the existing literature. Eur Urol. 2010;58(4):498-509

10. Wilson CH, Sanni A, Rix DA, Soomro NA. Laparoscopic versus open nephrectomy for live kidney donors. Cochrane Database Syst Rev. 2011;(11):CD006124.

11. Dols LF, Kok NF, ljzermans JN. Live donor nephrectomy: a review of evidence for surgical techniques. Transpl Int. 2010;23(2):121-30.

12. Maroun M, Anthony KC, Samir R, Fouad A, Fouad N, David A, Samir M, Chebl M. LIVING DONOR NEPHRECTOMY: OPEN vs LAPARASCOPY. Renal Function and Complications. I Med Liban. 2015;63:144-9. PMID: 26591194

13. He B, Bremner A, Han $Y$, Hamdorf IM. Determining the Superior Technique for Living-donor Nephrectomy: the Laparoscopic Intraperitoneal Versus the Retroperitoneoscopic Approach. Exp Clin Transplant 2016;14:129-38. PMID: 27015530

14. Elmaraezy A, Abushouk Al, Kamel M, Negida A, Naser O. Should hand-assisted retroperitoneoscopic nephrectomy replace the standard laparoscopic technique for living donor nephrectomy? A meta-analysis. Int | Surg 2017;40:83-90. PMID: 28216391

\section{Final declaration}

The Guidelines Project, an initiative of the Brazilian Medical Association in partnership with the Specialty Societies, aims to reconcile medical information to standardize approaches that can aid the physician's reasoning and decision-making process. The information contained in this project must be submitted to the evaluation and criticism of the physician, responsible for the conduct to be followed, given the reality and clinical condition of each patient.

15. Khalil A, Mujtaba MA, Taber TE, Yaqub MS, Goggins W, Powelson I, et al. Trends and outcomes in right vs. left living donor nephrectomy: an analysis of the OPTN/UNOS database of donor and recipient outcomes-should we be doing more right-sided nephrectomies? Clin Transplant 2016:30:145-53. PMID: 26589133

16. Wang K, Zhang P, Xu X, Fan M. Right Versus Left Laparoscopic Living Donor Nephrectomy: A Meta-Analysis. Exp Clin Transplant 2015;13:214-26. PMID: 26086831

17. Bandín Musa AR, Montes de Oca |. Hand-assisted Laparoscopic Nephrectomy in Living-donor Kidneys With Multiple Arteries: Experience of a Transplant Center Exp Clin Transplant. 2016;14:153-6. PMID: 27015532

18. Cooper M, Kramer A, Nogueira JM, Phelan M. Recipient outcomes of dual and multiple renal arteries following 1000 consecutive laparoscopic donor nephrectomies at a single institution. Clin Transplant 2013;27:261-6. PMID: 23305411

19. Carter JT, Freise CE, McTaggart RA, Mahanty HD, Kang SM, Chan SH, et al. Laparoscopic procurement of kidneys with multiple renal arteries is associated with increased ureteral complications in the recipient. Am J Transplant 2005:5:1312-8.

20. Hsu TH, Su Li, Ratner LE, Trock BJ, Kavoussi LR. Impact of renal artery multiplicity on outcomes of renal donors and recipients in laparoscopic donor nephrectomy. Urology 2003;61:323-7.

21. Lafranca $\mid A$, Hagen $S M$, Dols LF, Arends LR, Weimar W, ljzermans JN, et al. Systematic review and meta-analysis of the relation between body mass index and short-term donor outcome of laparoscopic donor nephrectomy. Kidney Int 2013;83(5):931-9. PMID: 23344469

22. Bhattu AS, Ganpule A, Sabnis RB, Murali V, Mishra S, Desai M. Robot-Assisted Laparoscopic Donor Nephrectomy vs Standard Laparoscopic Donor Nephrectomy: A Prospective Randomized Comparative Study. J Endourol 2015;29:1334-40. PMID: 26414847

23. Liu XS, Narins HW, Maley WR, Frank AM, Lallas CD. Robotic-assistance does not enhance standard laparoscopic technique for right-sided donor nephrectomy. JSLS 2012;16:202-7.

24. Renoult E, Hubert J, Ladriere M, Billaut N, Mourey E, Feuillu B, et al. Robot-assisted laparoscopic and open live-donor nephrectomy: a comparison of donor morbidity and early renal allograft outcomes. Nephrol Dial Transplant 2006;21:472-7.

25. Aull MJ, Afaneh C, Charlton M, Serur D, Douglas M, Christos PJ, et al. A randomized, prospective, parallel group study of laparoscopic versus laparoendoscopic single site donor nephrectomy for kidney donation. Am J Transplant 2014;14:1630-7. PMID: 24934732

26. Kurien A, Rajapurkar S, Sinha L, Mishra S, Ganpule A, Muthu V, et al. First prize: Standard laparoscopic donor nephrectomy versus laparoendoscopic single-site donor nephrectomy: a randomized comparative study. J Endourol 2011;25:365-70.

27. Richstone L, Rais-Bahrami S, Waingankar N, Hillelsohn $J H$, Andonian S, Schwartz MJ, et al. Pfannenstiel laparoendoscopic single-site (LESS) vs conventional multiport laparoscopic live donor nephrectomy: a pro- 
spective randomized controlled trial. BJU Int 2013;112:616-22. PMID: 23826907

28. Gupta A, Ahmed K, Kynaston HG, Dasgupta P, Chlosta PL, Aboumarzouk OM. Laparoendoscopic single-site donor nephrectomy (LESS-DN) versus standard laparoscopic donor nephrectomy. Cochrane Database Syst Rev 2016;(5):CD010850. PMID: 27230690

29. Levels of Evidence and Grades of Recommendations - Oxford Centre for Evidence Based Medicine. Disponível em http://www.cebm.net/ blog/2009/06/11/oxford-centre-evidence-based medicine-levels-evidence-march-2009.

30. Jadad AR, Moore RA, Carroll D, Jenkinson C, Reynolds DJ, Gavaghan DJ, et al. Assessing the quality of reports of randomized clinical trials: is blinding necessary? Control Clin Trials 1996; 17:1-12
31. Wells G, Shea B, O'Connell D, Robertson J, Peterson J, Welch V, et al. The Newcastle-Ottawa Scale (NOS) for assessing the quality of nonrandomised studies in meta-analyses. Disponível em: http://www.ohri.ca/ programs/clinical_epidemiology/oxford.asp.

32. Shea BJ, Hamel C, Wells GA, Bouter LM, Kristjansson E, Grimshaw J et al. AMSTAR is a reliable and valid measurement tool to assess the methodological quality of systematic reviews. | Clin Epidemiol 2009; 62:1013-20. PMID: 19230606 (http://amstar.ca/Amstar_Checklist. php)

33. Guyatt G, Gutterman D, Baumann MH, Addrizzo-Harris D, Hylek EM, Phillips B et al. Grading strength of recommendations and quality of evidence in clinical guidelines: report from an american college of chest physicians task force. Chest 2006;129(1):174-81. PMID: 16424429 